\title{
From the Journal archives: Epidural anesthesia in young children: What have we learned in the past 60 years?
}

\author{
Robin G. Cox, MBBS
}

Received: 24 June 2013/Accepted: 11 October 2013/Published online: 19 November 2013

(c) Canadian Anesthesiologists' Society 2013

\section{Editors' Note: Classics Revisited \\ Key Articles from the Canadian Journal of Anesthesia Archives: 1954-2013}

As part of the Journal's $60^{\text {th }}$ anniversary Diamond Jubilee Celebration, a number of seminal articles from the Journal archives are highlighted in the Journal's $61^{\text {st }}$ printed volume and online at: www.springer.com/12630. The following article was selected on the basis of its novelty at the time of publication, its scientific merit, and its overall importance to clinical practice: Ruston $F G$. Epidural anaesthesia in infants and children. Can Anaesth Soc J 1954; 1: 37-44. Dr. Robin Cox provides expert commentary on some innovative pioneering work related to an important regional technique in pediatric anesthesia.

Hilary P. Grocott MD, Editor-in-Chief

Donald R. Miller MD, Former Editor-in-Chief

\section{Summary}

Author Francis G. Ruston MD

Citation Ruston FG. Epidural anaesthesia in infants and children. Can Anaesth Soc J 1954: 1: 37-44.

Purpose The author describes the use of single-shot epidural anesthesia in a series of 44 infants and children. The patients were anesthetized in hospitals in Hamilton, Ontario from 1949 until the time of publication in 1954.

R. G. Cox, MBBS ( $\square)$

Department of Anesthesia, Alberta Children's Hospital,

University of Calgary, 2888 Shaganappi Trail N.W., Calgary,

AB T3B 6A8, Canada

e-mail: robin.cox@albertahealthservices.ca
The study aimed to describe the indications and efficacy of this technique as well as any apparent complications. A detailed description of the management of these patients was given, including many tips and suggestions that are still applicable in 2013.

Principal findings Seventy-seven infants and children received epidural anesthesia for a variety of procedures, particularly for pyloric stenosis. Forty-four of the procedures were carried out by the author. All patients survived, apart from one child who died of recurrent intestinal obstruction unrelated to the anesthetic. It was found, after some experience, that the sitting position was preferable for epidural needle insertion. Use of the hanging drop technique for identification of the epidural space proved to be simple and reliable. Surgical conditions were found to be excellent and relaxation was profound; however, some sedation was often required to obtain optimal conditions for surgery. The surgeons became sold on the technique and began to request an epidural on a regular basis. Conclusions Epidural anesthesia in infants and young children is effective for a variety of procedures below the diaphragm, even in moribund patients.

Francis G. Ruston MD, of Hamilton, Ontario gave us a thought-provoking account of his department's experience with epidural anesthesia in infants and children. His article was published in 1954 in the inaugural volume of The Canadian Anaesthetists' Society Journal, as the Journal was then titled. ${ }^{1}$ In common with many such articles in the Journal, this publication followed a presentation given at a conference - in this case, the Ontario Division of the Canadian Anaesthetists' Society. Ruston carried on this remarkable work in 1957 with a further publication in Anesthesia and Analgesia on the same topic. ${ }^{2}$ 
Ruston's work can only be described as truly pioneering. Following medical school at the University of Western Ontario and residency in Hamilton, Ruston served in the Canadian Army Medical Corps in both Canada and Europe and obtained the rank of major. He became interested in epidural anesthesia while overseas during the last part of World War II and used the procedure while working in Canadian Military Hospitals. Back in Hamilton in 1949, he decided that use of epidural anesthesia might be a suitable option when confronted with a moribund infant with pyloric stenosis, and this proved to be the case. After this promising start, Ruston proceeded to use epidural anesthesia for a wide variety of surgical procedures in infants and children. He clearly persuaded his colleagues that this was a valuable technique. In his paper, he details 44 cases that were personally conducted by him and comments that a further 33 cases were performed by other department members. At the time Ruston embarked on using epidural anesthesia in young children, the technique was virtually unknown in this age group. Prior to his article, Ruston could find only one reference to epidural anesthesia in children, i.e., a German publication by Sievers in 1936. Therefore, Ruston was clearly breaking new ground. Initially, Ruston's methods were not generally accepted and even condemned by some, ${ }^{3}$ but gradually others came to accept the important role of epidural anesthesia for pediatric patients. ${ }^{4}$

Many aspects of Ruston's paper are worthy of comment. The first concerns the nature of the patients whom he treated. He described the first patient as "moribund" - a baby with pyloric stenosis. Indeed, of the 44 cases described in some detail, 20 had pyloric stenosis. Other members in Ruston's department used epidural anesthesia in a further 32 babies with pyloric stenosis. So, pyloric stenosis was by far the commonest indication for epidural anesthesia in this series. Ruston describes the surgical procedure as "pyloroplasty". It might be supposed that these were pyloromyotomies, as this technique was described by Ramstedt in 1911. It may also be suspected that these babies may have presented with a longer history and more dehydrated than currently occurs. It is noteworthy that over half the cases of pyloric stenosis in this series were treated without intravenous infusions unthinkable in 2013. Ruston does not comment on the degree of dehydration or electrolyte/acid-base imbalance in these infants, but it might well be assumed that they were less well resuscitated than they would be today.

The other cases in the series included many complex and potentially unstable patients. For example, Ruston describes a newborn undergoing a liver lobe resection, two young children with generalized peritonitis from appendicitis, four infants with intussusception, and one infant with volvulus - challenging cases even today.
Ruston describes the intussusceptions as "desperate", and the patient with volvulus was "convulsing intermittently before operation and was moribund". It seems that Ruston chose to include such potentially sick and unstable cases as he believed epidural anesthesia might actually be safer than full general anesthesia or even spinal anesthesia. Ruston reminded the reader that many hospitals at the time did not have anesthesia machines suitable for use in infants and small children; the added risk of intubation was a factor to consider, and epidural anesthesia might be more controllable than spinal anesthesia.

Ruston describes in some detail the technique of epidural anesthesia that he used. He was clearly influenced by the work of the Italian surgeon, Prof. A. Mario Dogliotti, who popularized the technique in 1933 following earlier work by the Spanish military surgeon, Fidel Pagés. Dogliotti was an advocate of the loss of resistance technique using a syringe filled with a "physiological solution".5 Ruston did use Dogliotti's technique for some of his patients as well as an earlier technique that involved performing a spinal tap and then withdrawing the needle until the flow of cerebrospinal fluid ceased prior to making the epidural injection. Overall, however, Ruston favoured the disappearing or hanging drop technique. Ruston stressed the importance of positioning when performing the block. After some problems with the lateral position, he determined that the sitting position was most suitable and that the infant must be held firmly in a flexed position. For this positioning, an assistant is needed to clasp the infant's elbows and knees together. In all probability, this position contributed to the negative pressure required for the hanging drop technique. Subsequently, other workers have successfully employed a hybrid of the hanging drop and loss of resistance techniques, notably Masao Yamashita of Japan who describes the application of a microdrip infusion set to a Tuohy needle. ${ }^{6}$ Other more recently described techniques for identifying the epidural space in children have included nerve stimulation guidance ${ }^{7}$ and ultrasound. ${ }^{8}$ Currently, it is safe to say that the loss of resistance technique using saline is the most widely accepted method of identifying the epidural space, at least in Canada. ${ }^{9}$ Ames et al. present a detailed discussion of the arguments in favour of saline over air for identifying the epidural space in infants and children; perhaps the most important argument is minimizing the risk of venous air embolism. ${ }^{9}$

Ruston was somewhat limited by the needles available to him. The early design of Tuohy needles were both sharp and of wide diameter ${ }^{10}$ and therefore would not have been suitable. Ruston favoured a $22 \mathrm{G}$ or $20 \mathrm{G}$ short bevelled spinal needle with stylet and added flanges. He states that "rarely does one do a spinal tap if the drop is closely observed", but he does not provide exact numbers for this 
complication. Presumably, the numbers would have been even lower if he had access to the short blunt epidural needles we use today.

Another interesting feature of Ruston's series is that he did use sedative premedication and supplemental anesthetic sedating drugs as part of the technique. Premedication generally followed the schedule recommended by Leigh and Belton that was based around an opiate such as morphine with an anticholinergic. Alternatively, a rectal barbiturate was suggested. Unlike Leigh and Belton, however, Ruston preferred codeine over morphine, being concerned about the risk of morphine "in a training school hospital". Why morphine would be more prone to dosing errors than codeine was not made clear. These days, we would very likely not use any premedication, particularly in the population of patients described.

It is noteworthy that Ruston did use supplementary sedation in over half of his patients during the surgical procedure. The commonest agent he used was a "minute amount" of thiopental, but on occasion, he also used nitrous oxide or "light" cyclopropane by facemask. The indication for these agents was restlessness, and it is not clear if these supplements were ever administered prior to the epidural injection. The issue of whether it is safe to perform epidural anesthesia under general anesthesia or sedation has been the topic of much argument in recent years, but the consensus in the pediatric anesthesia world is that this is an acceptable practice. ${ }^{11}$ Considering the nature of the patients in Ruston's series, it was very reasonable for him to minimize his doses of supplements given the risk of hemodynamic instability and/or pulmonary aspiration.

Ruston does provide details of his patient outcomes in his series, and in general, these were good. There was only one death out of the 77 patients, and that was an infant who died three weeks postoperatively from recurrence of jejunal atresia - not a cause related to the anesthesia. There was one case of a "subcutaneous reaction to old blood" in an intravenous needle that was being reused for administration of the epidural anesthetic; one forgets that reuse of items such as hypodermic needles was common practice sixty years ago. Convulsions occurred in three cases, but Ruston considered this unrelated to the dose of lidocaine used. He came to believe that $1 \%$ lidocaine with $1: 200,000$ of epinephrine was the preferred local anesthetic mixture and that $5-6 \mathrm{~mL}$ of this solution would be enough for the "average infant". Nowadays, this would be considered a toxic dose for most infants. Ruston did not have access to the potentially more cardiotoxic drug, bupivacaine, which did not appear in clinical practice until 1965. Consequently, the need for agents, such as Intralipid, to reverse cardiotoxic complications was less necessary in 1954.

Since Ruston's remarkable series, there have been many publications attesting to the safety and efficacy of epidural anesthesia in children. Wood concluded that the majority of complications associated with the use of epidurals in children were minor and easily remedied. ${ }^{12}$ The FrenchLanguage Society of Pediatric Anesthesiologists has been pivotal in reporting surveys of regional anesthesia in children. ${ }^{13}$ Their most recent publication ${ }^{14}$ included 10,098 pediatric epidurals, many of them administered via the caudal route. There were ten dural taps recorded for an incidence of less than 1:1000. The overall complication rate was very low, and there were no instances of permanent harm in any patient after one year.

A further study of great importance was the National Pediatric Epidural Audit conducted in the United Kingdom in which 10,633 pediatric epidurals were evaluated over a five-year period. ${ }^{15}$ Only one case of persistent neurological damage was recorded, which occurred in a $3.2-\mathrm{kg}$ fourmonth-old who developed cauda equina syndrome due to an infusion pump malfunction. As reported in 2012, important work on the topic of complications of pediatric regional anesthesia is being conducted in the USA by the Pediatric Regional Anesthesia Network (PRAN). ${ }^{16}$ Fourteen pediatric centres contributed information to a central database. Included in this series were 2,946 neuraxial blocks involving catheter insertion. The commonest adverse events were catheter related (dislodgement or kinking), and the cumulative failure rate was low (2\%). There were 21 complications of a serious nature (e.g., postdural puncture headache), but no complication resulted in sequelae lasting more than three months. A single-centre Canadian study of 3,152 pediatric epidurals would seem to echo the PRAN report with results showing a major complication rate of $0.76 \% .^{17}$ Hence, it would seem that Ruston's initial impression that epidural anesthesia is generally safe in children has been supported in more recent studies. Although Ruston's data were largely retrospective in nature and potentially may have underreported complications, his major outcome finding, namely, zero mortality associated with the anesthetic technique, cannot be disputed.

Nevertheless, it cannot be taken for granted that epidural anesthesia in children is entirely without risk. A recent series of four children who sustained long-term or permanent neurological complications associated with epidural anesthesia is concerning. ${ }^{18}$ In an accompanying editorial, ${ }^{19}$ Berde and Greco suggest that, despite the worrying nature of these four cases, they still represent rare events compared with the cumulative denominator from published case series. This editorial goes on to identify ten provisional recommendations to lower this risk even further, including the avoidance or prompt treatment of severe hypotension, the use of saline for loss of resistance tests, and the intraoperative use of slow injections of relatively dilute solutions. Anesthesiologists who perform 
epidural anesthesia in children would be well advised to consider these recommendations.

Ruston must be given much credit for introducing a technique that at the time must have seemed quite radical a technique that produced excellent results and might well have saved lives in his institution at the time. Several of his conclusions are still valid today. For instance, he states that "There is a certain risk which depends to a great degree on the skill of the anaesthesiologist. No one should attempt such an anaesthetic unless he has considerable experience in adult epidurals." No doubt the skill and experience of Dr. Ruston contributed to his good outcomes, which must have been crucial when obtaining the support of both pediatricians and surgeons. Had serious complications occurred due to the anesthetic technique, progress in the field of pediatric regional anesthesia might have been set back for many years. As it transpired, Ruston's excellent results led the surgeons to change from being slightly skeptical to being agreeably impressed - often requesting "one of those epidural blocks".

\section{Key points}

- Epidural anesthesia was proven to be a useful technique in infants and children undergoing a wide variety of procedures.

- The hanging drop technique for identification of the epidural space was reliable in this series.

- Epidural anesthesia in children can be performed following sedative premedication and may be supplemented during surgery with small doses of general anesthetic agents.

- Positioning and appropriate restraint is particularly important when performing epidurals in children.

- Surgeons can be persuaded to support novel anesthesia techniques that are found to be safe and effective. This is as true today as it was in 1954 .

Financial support No financial support was required for this article.

Conflicts of interest None declared.

\section{References}

1. Ruston FG. Epidural anaesthesia in infants and children. Can Anaesth Soc J 1954; 1: 37-44.
2. Ruston FG. Epidural anaesthesia in pediatric surgery. Anesth Analg 1957; 36: 76-82.

3. Bosenberg A. Regional anesthesia: central neuraxial blocks. In: Bissonnette B, editor. Pediatric Anesthesia - Basic PrinciplesState of the Art-Future. Shelton, CN: PMPH-USA; 2011. p. 806.

4. Dalens B, Tanguy A, Haberer JP. Lumber epidural anesthesia for operative and postoperative pain relief in infants and young children. Anesth Analg 1986; 65: 1069-73.

5. Dogliotti AM. Research and clinical observations on spinal anesthesia: with special reference to the peridural technique. Anesth Analg 1933; 12: 59-65.

6. Yamashita $M, T s u j i$ M. Identification of the epidural space in children. The application of a micro-drip infusion set. Anaesthesia 1991; 46: 872-4.

7. Tsui BC, Seal R, Koller J, Entwistle L, Haugen R, Kearney $R$. Thoracic epidural analgesia via the caudal approach in pediatric patients undergoing fundoplication using nerve stimulation guidance. Anesth Analg 2001; 93: 1152-5.

8. Rapp HJ, Folger A, Grau T. Ultrasound-guided epidural catheter insertion in children. Anesth Analg 2005; 101: 333-9.

9. Ames WA, Hayes JA, Petroz GC, Roy WL. Loss of resistance to normal saline is preferred to identify the epidural space: a survey of Canadian pediatric anesthesiologists. Can J Anesth 2005; 52: 607-12.

10. Frolich MA, Caton D. Pioneers in epidural needle design. Anesth Analg 2001; 93: 215-20.

11. Krane EJ, Dalens BJ, Murat I, Murrell D. The safety of epidurals placed during general anesthesia. Reg Anesth Pain Med 1998; 23: 433-8.

12. Wood CE, Goresky GV, Klassen KA, Kuwahara B, Neil SG. Complications of continuous epidural infusions for postoperative analgesia in children. Can J Anaesth 1994; 41: 613-20.

13. Giaufre E, Dalens B, Gombert A. Epidemiology and morbidity of regional anesthesia in children: a one-year prospective survey of the French-Language Society of Pediatric Anesthesiologists. Anesth Analg 1996; 83: 904-12.

14. Ecoffey C, Lacroix F, Giaufre E, Orliaguet G, Courreges P; Association des Anesthésistes Réanimateurs Pédiatriques d'Expression Française (ADARPEF). Epidemiology and morbidity of regional anesthesia in children: a follow-up oneyear prospective survey of the French-Language Society of Paediatric Anaesthesiologists (ADARPEF). Pediatr Anesth 2010; 20: 1061-9.

15. Llewellyn $N$, Moriarty A. The national pediatric epidural audit. Pediatr Anesth 2007; 17: 520-33.

16. Polaner DM, Taenzer AH, Walker BJ, et al. Pediatric Regional Anesthesia Network (PRAN): a multi-institutional study of the use and incidence of complications of pediatric regional anesthesia. Anesth Analg 2012; 115: 1353-64.

17. Wong GK, Arab AA, Chew SC, Naser B, Crawford MW. Major complications related to epidural analgesia in children: a 15 -year audit of 3,152 epidurals. Can J Anesth 2013; 60: 355-63.

18. Meyer MJ, Krane EJ, Goldschneider KR, Klein NJ. Neurological complications associated with epidural anesthesia in children: A report of 4 cases of ambiguous etiologies. Anesth Analg 2012; 115: $1365-70$.

19. Berde C, Greco C. Pediatric regional anesthesia: drawing inferences on safety from prospective registries and case reports. Anesth Analg 2012; 115: 1259-62. 